\title{
Policy gaps and technological deficiencies in social networking environments: Implications for information sharing
}

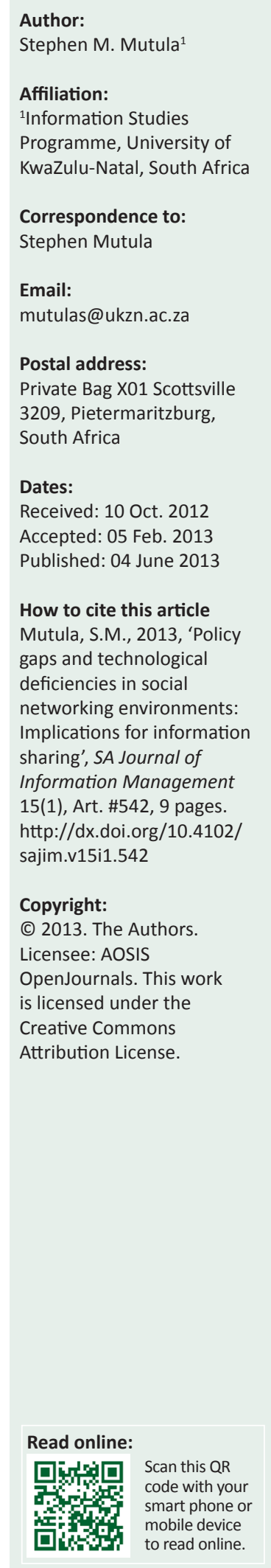

Background: With the growing adoption and acceptance of social networking, there are increased concerns about the violation of the users' legitimate rights such as privacy, confidentiality, trust, security, safety, content ownership, content accuracy, integrity, access and accessibility to computer and digital networks amongst others.

Objectives: The study sought to investigate the following research objectives to: (1) describe the types of social networks, (2) examine global penetration of the social networks, (3) outline the users' legitimate rights that must be protected in the social networking sites (SNS), (4) determine the methods employed by SNS to protect the users' legitimate rights and (5) identify the policy gaps and technological deficiencies in the protection of the users' legitimate rights in the SNS.

Method: A literature survey and content analysis of the SNS user policies were used to address objective four and objective five respectively.

Results: The most actively used sites were Facebook and Twitter. Asian markets were leading in participation and in creating content than any other region. Business, education, politics and governance sectors were actively using social networking sites. Social networking sites relied upon user trust and internet security features which however, were inefficient and inadequate.

Conclusion: Whilst SNS were impacting people of varying ages and of various professional persuasions, there were increased concerns about the violation and infringement of the users' legitimate rights. Reliance on user trust and technological security features SNS to protect the users' legitimate rights seemed ineffectual and inadequate.

\section{Introduction}

The social networking sites are impacting people of varying ages and of various professional persuasions, both in the developed and the non- developed world and have quickly gained acceptance and use in education, research, the corporate world, government, politics, professional practice, and in the general society. With the growing adoption and acceptance of social networking, there are increased concerns about the violation and infringement of the users' legitimate rights. The concept 'legitimate right' is used in this study to infer legal and moral rights - that is, valid claims by individuals on society to protect them from being denied the entitlement of human well-being on grounds of their utility through the force of law, or by education (Mill 1969). The legitimate rights discussed in this study include but are not limited to privacy, confidentiality, trust, security, safety, content ownership, content accuracy and integrity, access and accessibility. These rights are both legal and moral (Hart 1994), a fact emphasised by Wellman (1995) who avers that the core concept of a right is something common to the law and morality.

The purpose of this study was to investigate how the users' legitimate rights in the social networking environments were being protected. A social networking site refers to a public webbased space that allows individuals to create their profile, articulate a list of other users with whom they share a connection, view and traverse their list of connections in a reciprocal manner (Privacy Rights Clearing House 2012). The social networking sites are part of the wider social media - a group of internet based applications that build on the ideological and technological foundation of Web 2.0 and allow the creation and exchange of the user generated content (Kaplan \& Haenlein 2010). The social media incorporates wikis, blogs, social bookmarking, internet forums, online communities, RSS feeds, tag-based folksonomies, podcasts, e-mail, virtual worlds, and instant messaging amongst others (Kaplan \& Haenlein 2010). This study focused on the social networking sites particularly Facebook, Twitter, LinkedIn, Google+, Myspace, and YouTube because they are the market leaders in the industry (Lewis 2010). 
This study was underpinned by the classical and the contemporary ethical traditions. From the classical traditional perspective, early scholarly engagement with regard to protecting legitimate rights of the users drew considerable insights from utilitarianism and deontology realms (Giles 2006; Boyd 2007). However, there is growing debate on whether the classical ethical traditions possess sufficient resources to illuminate the ethical implications of emerging information technologies such as the social networking or whether we need new ethical instruments. Kaplan and Haenlein (2010) therefore argue that the contemporary ethical traditions founded on computer ethics and philosophies of technology are needed to analyse how particular moral issues are embedded in the specific technologies. The contemporary ethical traditions include disclosive ethics; global information ethics; pragmatism (Van den Eede 2010); virtue ethics (Vallor 2010); feminist and care ethics (Hammington 2010) and intercultural information ethics (Capurro 2010). The contemporary ethical traditions largely define ethical standards in technological environments and consequently expand the scope and milieu of 'legitimate rights' beyond what is conventionally provided for by the classical traditions. The classical ethical traditions focus on privacy, confidentiality, contextual integrity, and freedom; whilst the contemporary ethical traditions add on this milieu access and accessibility, accuracy, security, trust, illegal surveillance, identity theft, intellectual property and copyright (World Summit on the Information Society [WSIS] 2005; Kaplan \& Haenlein 2010; Mason 1986). This study focused on the legitimate rights proffered by both classical and contemporary traditions.

\section{Research problem}

There are several issues affecting the protection of the users' legitimate rights in the social networking environments. Evidence is growing that show the social networking service providers are neither keen nor able to protect the legitimate rights of the users. This behaviour may be attributed to the fact that the main marketing business model of the social networking service providers is based on the ownership of their customers' revealed information about themselves (Capurro 2010). For example, Facebook in September 2012 changed its user privacy policy, thus effectively depriving the users the right to vote on matters affecting them. The implications of Facebook policy change is that the users' content can be shared with third parties without their [users'] consent (Privacy Rights Clearinghouse 2012). Additionally, the affiliates or approved contacts of the SNS may copy and repost information without the users' permission (Privacy Rights Clearinghouse 2012). Nissenbaum (2004) in this regard points out that privacy is about context and the consequences of sharing the users' data without their consent is unethical and a violation of their privacy. The users' policies of the social networking sites invariably acknowledge that the content uploaded onto the sites is not necessarily guaranteed security because such content may be accessed by cookies. Zabala (2012) therefore points out that the more one enters social networking sites, the more one gets locked in - a closed silo of content, and one that does not give one full control over one's information in it. Similarly, Lovink (2011) asserts that in Facebook, individuals are not only tricked but also trick themselves into believing that they are free in creating and discovering their identity, when on the contrary they are prisoners of Facebook's - predefined choices, sentenced with the burden and illusion of endless - possibilities. Lovink (2011) concludes that we should no longer be naïve and trust commercial companies who deliver free services and take the responsibility of [defining our lives].

The issues about the users' legitimate rights in the SNS are weighty and require in-depth investigation to find the scope and extent of violations of such rights and how the situation can be ameliorated. It is for this reason that this study investigated the following research objectives.

\section{Research objectives}

This study sought to investigate how the legitimate rights of the users in social networking sites are being protected. The following objectives were addressed, to:

1. Describe the types of social networks.

2. Examine global penetration of the social networks.

3. Outline the users' legitimate rights that must be protected in the social networking sites.

4. Determine the methods employed by SNS to protect the users' legitimate rights.

5. Identify the policy gaps and technological deficiencies in the protection of the users' legitimate rights in the SNS.

\section{Research design}

A literature survey and content analysis were used to address the above research objectives. A literature review was used particularly to address objective one to objective three whilst content analysis of the social networking user policies was used to address objective four and objective five respectively. A literature survey was useful in providing the background information about the SNS with regard to global penetration and in unravelling the users' legitimate rights which must be protected. The content analysis of the user policies was helpful in identifying the policy gaps and technological deficiencies in the protection of the users' legitimate rights in the social networking environments. The user policies analysed were those of Facebook, Twitter, LinkedIn, Google+ and YouTube. These social networking sites were selected because they are the market leaders in the social networking industry. In reviewing the user policies, focus was placed on the user privacy guarantees, the methods of enforcing compliance with the policies, compensation when the users' rights are violated, the sanctions meted on errant users, verification of the credibility of information uploaded by the users, the role and responsibilities of the users, user training, intellectual property rights, and guarding servers against invasion.

The study was underpinned by both the classical and the contemporary ethical traditions. The classical tradition pervades early scholarly engagement with regard to 
protection of legitimate rights of the users and drew considerable insights from utilitarianism and deontological realms. The contemporary ethical traditions draw from computer ethics and philosophy of technology (Kaplan \& Haenlein 2010; Giles 2006; Boyd 2007). The two ethical traditions define the milieu of 'legitimate rights' that must be protected in the social networking environments.

\section{Results}

The purpose of this study was to investigate how the legitimate rights of the users in the social networking sites are being protected. The study specifically sought to:

1. Describe the types of social networks.

2. Examine global penetration of the social networks.

3. Outline the users' legitimate rights that must be protected in the social networking sites.

4. Determine the methods employed by SNS to protect the user's legitimate rights.

5. Identify the policy gaps and technological deficiencies in the protection of the users' legitimate rights in the SNS.

The results based on each of the above research objectives are outlined in the sections that follow.

\section{Types of the social networks}

From the literature reviewed, five different types of the social networks (Privacy Rights Clearinghouse 2012) were identified namely - personal networks, status update networks, location networks, content sharing networks and shared interest networks. The personal networks allow the users to create detailed online profiles and connect with other users with emphasis on social relationships. The examples here include Facebook and MySpace. On the other hand, the status-update networks refer to social networks designed to allow the users to post short status updates in order to communicate with other users quickly. In this category, the example used is Twitter. In contrast, the location networks are founded on global positioning systems (GPS) technology and are designed to broadcast one's real-time location, either as public script or as an update viewable to authorised contact. The examples of the location networks include Google Latitude, Foursquare and Loopt. Besides, the content sharing networks are designed for sharing content including verbal and text-based exchanges, music, photographs and videos. In this category, YouTube and Flickr are the examples used amongst others. Finally, the shared interest networks are built around common interest of a specific group of people. These types of networks include amongst others LinkedIn. This study focused on the personal networks, the status update networks, the content sharing networks and the shared interest networks. The following social networking sites were therefore covered Facebook and Myspace, Twitter, YouTube and LinkedIn from the personal networks, the status update networks, the content sharing networks, and the shared interest networks categories respectively. The SNS from each of these categories are the most popular and widely used.

\section{Global penetration of the social networks}

The literature reviewed found that the social networking activity is growing phenomenally across the world with Facebook being the most widely used social networking site having exceeded a billion active accounts by October 2012 (Privacy Rights Clearing House 2012). Moreover, of the active Facebook users, 526 million used the site on daily basis (Backstrom, Dwork \& Keinberg 2011). Globally, the Asian markets in general were found to be leading in terms of participation and in creating more content than any other region (Smith 2011). For example, in 2011, Philippines had a penetration of $83 \%$, Hungary $80 \%$, Poland $77 \%$, and Mexico $76 \%$ with the growth areas worldwide being in the video clips (83\%); the social networks (57\%); the widget economy (the social network users with installed applications) (23\%) and the blogging community (42 million bloggers) (Smith 2011). The results also indicated that Africa was not left behind and reached 48 million users in 2012 distributed as follows: 30 million users on Facebook, 6 million users on LinkedIn and 12 million users on Twitter (Mathen 2012). Most tweets (57\%) in Africa were reportedly emanating from mobile devices (Onyango 2012). Furthermore, in 2012, the leading African countries on Facebook in terms of the user active accounts were Egypt (9.4 million), South Africa (4.8 million) and Nigeria (4.4 million) (Katlic 2012). Facebook was rated the most popular social networking site with an estimated between 550 million and 750 million monthly visitors in 2011 (eBizMBA 2011; Arico 2011). In addition, the largest demographic group on Facebook was those aged 35 to 54 years followed by those aged 18 to 24 years (Generation Y and Generation Z, respectively) (Corbet 2010). The fast growth of the social networking phenomenon globally may be attributed to the fact that traditional collaborative technologies such as the e-mail, and the telephone which are largely text and document-centred have become less efficient to drive innovation and productivity (Mathen 2012). Moreover, the rise of affordable handsets and the broadband connectivity was fuelling the spread of social networking activity. Farmington (2012), Chauke (2012) and Gosier (2008) are in agreement that the availability of cost-effective mobile and wireless solutions and the greater demand for connectivity has become the most important factors driving rapid growth of the social media.

The literature surveyed also found that the social networking sites were being applied to promote business as a new competitive tool with companies adopting the social software as a strategic part of their IT investment. In addition, companies have embraced the social software to bring about integration of disparate organisational units and workforce free of geographic constraints (Mathen 2012). In education, Rice (2011) pointed out that college students were using the social networking sites such as Facebook to communicate with each other about their coursework; writing status updates and posting pictures; and for social and educational purposes. 


\section{Users' legitimate rights that must be protected in the social networking sites}

With regard to the users' legitimate rights, Buchanan (2012) identified anonymity, confidentiality of data, data integrity and data security as areas raising greatest ethical concern. Kaplan and Haenlein (2010) on the other hand, outlined several legitimate rights to which individuals are entitled which included privacy, ownership and access. They pointed out that adequate provision must be made to protect the privacy of subjects and maintain the confidentiality of any data that were collected. They also stated that a violation of privacy or breach of confidentiality presented a risk of serious harm to [the users] arising from exposure of personal or sensitive information, the divulgence of embarrassing or illegal conduct or the release of data protected under the law. Van den Eede (2010), Vallor (2010), Hammington (2010), Skog (2011), Light, McGrath and Griffiths (2008) from the classical utilitarianism and deontology perspectives identified privacy, confidentiality, contextual integrity and freedom as the most critical ethical concern. In contrast, WSIS (2005), Kaplan and Haenlein (2010) and Mason (1986:5) in the context of the new information technologies identified the following legitimate rights- access or accessibility, accuracy, security, trust, illegal surveillance, identity theft, intellectual property and copyright. Mason (1986) went further and posed the questions that must be addressed in an electronic age in order to protect the users' legitimate rights. The questions that must be asked include: What information about one's self or one's associations should a person reveal to others and under what conditions and safeguards? Who has the responsibility for the authenticity, fidelity and accuracy of information?

Who is to be held accountable for the errors in the information? How can the injured party be made whole? Who has the ownership of [content] and the channels through which the information is transmitted? How should access to this [channels] be allocated? What kinds of information can a person or an organisation have a right to or a privilege to obtain, under certain conditions and safeguards? Echoing the same view as Mason, WSIS Action Line 10 pronounces in generic terms human rights that must be protected in an information society environment. Such human rights include (WSIS 2005): universally held values, the common good, the fundamental values of freedom, equality, solidarity, tolerance, and shared responsibility.

\section{Methods employed by the social networking sites to protect the users' legitimate rights}

The content analysis of the user policies revealed that Facebook like other SNS rely heavily on client trust and good will to safeguard their [clients'] rights (Facebook 2012). The results also found that the social networking service providers particularly Facebook expected the users to adhere to some basic standards of ethical behaviour (Facebook 2012). For example, Facebook has a 'statement of rights and responsibilities' for governing behaviour of the users on its sites (Facebook 2012). This 'statement of rights and responsibilities' expects the users to grant Facebook exclusive, transferable, worldwide license to use their content.

Facebook user policy states that the service provider does not allow those under the age of 13 years or sex offenders convicts to use their services. Furthermore, Facebook policy states that if the users post content on its platform which infringes or violates someone else's rights, the accounts of those gullible will be disabled (Facebook 2012). In this regard, Facebook (2012) user policy stipulates that:

If the client violates the letter or spirit of this Statement, or otherwise creates risk or possible legal exposure for us, we can stop providing all or part of Facebook to you. (n.p.)

In contrast, LinkedIn user policy states that the service provider does not provide personally identifiable information to the third parties without the user consent. Besides, the user policy states that LinkedIn provides the means to control viewing of customer contact information through the users' profile function. Like Facebook, LinkedIn policy states that the service provider does not accept abuse of LinkedIn service by the users who may wish to use it to spam, abuse, harass, or otherwise violate the User Agreement or Privacy Policy. Moreover, LinkedIn user policy states that it does not accept any information deemed to be injurious, violent, offensive, racist or xenophobic, or which may otherwise violate the purpose and spirit of LinkedIn and its community of users (LinkedIn 2012).

Google (2012) user policy dissuades illegal activities such as malicious products, hate speech, distributing personal and confidential information, account hijacking, distributing content that exploits children such as child pornography, unwanted promotional or commercial content, or unwanted or mass solicitation, sexually explicit material, violent or bullying behaviour. The YouTube Team (2012) in contrast states that every community features on its site involves a certain level of trust and every customer is therefore expected to comply with this requirement Furthermore, the YouTube policy asserts that the platform does not support pornography or sexually explicit content. The policy cautions the users to be aware that the YouTube Team works closely with law enforcement agencies and strives to report child exploitation. Furthermore, the policy states that it is against animal abuse, drug abuse, predatory behaviour, stalking, threats, harassment, invading privacy, hate speech, attacks, or humiliation. The policy says it respects copyright, free speech and defends everyone's right to express unpopular points of view.

\section{Policy gaps in the social networking environments}

The results from the content analysis exposed several gaps through which the users' legitimate rights are violated in the social networking sites. Steel and Vascellaro (2010) state that the social networking sites, particularly Facebook are confronted with an increasing scrutiny over their privacy practices from the consumers, the privacy advocates and the lawmakers. Various flaws are inherent in the user policies of 
the SNS. For example, largely all the SNS policies allow the advertising companies to harvest the users' information to meet their [companies'] commercial interests. In this regard, NSMNSS (2012) cautions the users that most of the social networking sites are commercially owned and for that matter are designed to generate revenue not simply for a social good but to encourage the users to navigate and participate in certain ways. Facebook has a new insertion in its data user policy that states:

we may share information we receive with businesses that are legally part of the same group of companies that [Facebook] is part of or become part of the group [the affiliates]. (Facebook Site Governance 2012)

This policy change was preceded by Facebook's announcement on 22 November 2012 that it would no longer let the users have a say in its privacy policy formulation. Besides, Facebook asks the users to make their personal information public in addition to requiring them to use their actual names whilst registering.

The social networking user policies generally indemnify the service providers from liability in the event of any litigation arising out of a breach of rights of their users or third parties. For example, Facebook (2012) user policy states:

If anyone brings a claim against us related to your [the user] actions and content, you will indemnify and hold us harmless from and against all damages, losses, and expenses of any kind (including reasonable legal fees and costs) related to such claim. (n.p.)

Twitter (2012) user policy in contrast states that it provides information to the law enforcement personnel seeking information about their users. Most of the Twitter profile information is public, so anyone can see it. The Twitter user policy like those of other major social networking sites only complies with the US law (Twitter 2012) and is not applicable in any other jurisdiction.

\section{Technological deficiencies in the social networking sites}

The technological gaps in the social networking environments are largely attributed to the security weaknesses of the internet technology. Danezis (2009) in this regard observes that the social networking sites have recently come under criticism for their poor privacy protection track record in part due to the internet's limited engineering features. The Privacy Rights Clearinghouse (2012) notes that identity thieves are a threat in the SNS as they obtain personal information based on the information a user posts online. The users on the SNS are vulnerable to online criminals who scam, harass and bully individuals. The criminals also use malware to infect content or computer programmes. Moreover, phishing attacks occur when e-mails, instant messages or other messages claiming to be from trusted sources ask for information. Additionally, hijacking of accounts occurs when a legitimate account is taken over by an identity thief for the purpose of fraud such as spamming or stealing private data.
Facebook like other SNS has no technological means of verifying the integrity, honesty, reliability, and accuracy of the information uploaded to their site by the users. Facebook acknowledges that there are no guarantees to ensure strict compliance with ethical provisions either through policy or technological interventions. In this respect, Facebook (2012) is explicit that:

...We do our best to keep Facebook safe, but we cannot guarantee it especially, when the users access Facebook, using automated means such as harvesting bots, robots, spiders, or scrapers without our permission; or upload viruses; use someone else's login; bully, intimidate, or harass any user... [In addition, Facebook does not guarantee that its platform is bug free, safe, and secure.] (n.p.)

Similarly, LinkedIn acknowledges that whereas personal information the user provides will be secured in accordance with the industry standards and technology, the internet is not a $100 \%$ secure environment, consequently, there is no guarantee that the information may not be accessed, copied, disclosed, altered, or destroyed by the breach of any of the physical, technical, or managerial safeguards (LinkedIn 2012).

Twitter (2012) points out that it does not have explicit ways of e-mail verification or identity authentication of its users. Besides, some information stored by Twitter is automatically collected. Twitter acknowledges that the information they store from the users may not be accurate if the user has created a fake or anonymous profile. LinkedIn (2012) in contrast supports tracking customers' action online whenever such customers view and/or interact with LinkedIn pages, mobile applications, software IP address, and browser type operating system.

\section{Discussion of results}

The purpose of this study was to investigate how the legitimate rights of the users in social networking sites were being protected. The discussion of the results is based on each of the research objectives paraphrased into the sectional headings below.

\section{Description of the different social networking sites}

The first objective of the study sought to describe types of the social networks. The results found five different types of social networks namely:

1. personal networks

2. status update networks

3. location networks

4. content sharing networks

5. shared interest networks. (Privacy Rights Clearinghouse 2012)

The personal networks seem to be the most popular form of social networking sites as revealed by the highest penetration of Facebook worldwide. The high penetration of Facebook may be attributed to the fact that at its very foundation it was established to create detailed online profiles and 
facilitate connecting of the users with emphasis placed on the social relationships. Furthermore, the high penetration of Facebook may also be due to the fact that it emerged as a way to link a university cohort, many of whom are students with active accounts on the site, to one another to promote their scholarship. Facebook also connects people across the globe and is increasingly used for business profiles aimed at establishing links with customers. In contrast, MySpace which is in the same category as Facebook does not seem to attract comparable numbers of clients. This may be attributed to the fact that Facebook is an established brand and a market leader. MySpace was established for musicians to promote their brand and communicate with their fans and was not meant for all the public.

In the category of the status-update networks, the results indicated that Twitter was the most well- known but second to Facebook in global penetration. The popularity of Twitter may be attributed to its suitability in creating lines of communications between ordinary individuals and figures of public interest. For this reason, it serves effectively as a tool for political or civic mobilisation. Twitter is also suited for mobile gadgets which are portable and provide platform for broadcasting text quickly rather than images which may require high bandwidth. The location networks which are designed to broadcast one's real-time location, either as public or as an update viewable to authorised contact does not seem to have penetrated as fast as personal and statusupdate networks presumably because it requires specialised software. In addition, people may not be inclined to reveal their location for various personal reasons such as privacy. The content sharing networks such as YouTube and Flickr grew out of the need to share and exchange verbal, text, music, photographs and videos. However, their growth slackened in part because all types of the social networks can support the exchange and sharing of all forms of media. Finally, shared interest networks in which LinkedIn is the most well-known are built around common interest of a specific group of people. LinkedIn is therefore more specialised as it encourages social relations organised around professional lives (Kaplan \& Haenlein 2010). This may perhaps explain why LinkedIn growth and penetration trails that of Facebook and Twitter. Weiss (2008) asserts that social networking activity in general has become a global phenomenon happening in all markets regardless of wider economic, social and cultural development and is now the number one online activity, accounting for $10 \%$ of all the users' time on the Internet (Lundsay 2010).

\section{Status of social networking penetration}

The second research objective of the study was to examine the global status of the social networks penetration. The results obtained from the literature reviewed found that the social networking was an online activity growing phenomenally across the world. Facebook was identified as the market leader in the industry and was the most widely used social networking site with over a billion active users in 2012 (Privacy Rights Clearing House 2012). Globally, the Asian markets in general were leading in terms of participation and in creating more content than any other region (Smith 2011). Africa which has traditionally lagged behind other regions in technological innovations performed well reportedly because of the fast growth of mobile phones. It is instructive that the political revolution in North Africa that overthrew the regimes of Ben Ali of Tunisia, Hussein Mubarak of Egypt and Muammar Kaddafi of Libya were orchestrated through the social networks by young people using mainly Twitter and Facebook to mobilise the masses. The dramatic penetration of the social networking activity in Africa was made possible by the fact that $57 \%$ of tweets are emanating from mobile devices (Onyango 2012).

\section{Users' legitimate rights in social networking sites}

The third research objective of the study was to describe the users' legitimate rights that must be protected in the social networking environments. The results indicated that legitimate rights of individuals are underpinned by both the classical and the contemporary ethical traditions which collectively include pragmatism; virtue ethics; feminist and care ethics, intercultural information ethics, WSIS Action Line 10, Mason's ethical issues in electronic age, disclosive ethics; global information ethics; and intercultural information ethics (WSIS 2005; Kaplan \& Haenlein 2010; Mason 1986; Van den Eede 2010; Vallor 2010; Hammington 2010 \& Capurro 2010). The milieu of 'legitimate rights' gleaned from the two categories of ethical traditions were privacy, confidentiality, contextual integrity, access or accessibility, accuracy, security, trust, illegal surveillance, identity theft, intellectual property and copyright (WSIS 2005; Kaplan \& Haenlein 2010).

\section{Protection of the user's legitimate rights in social networking sites}

The fourth research objective was to determine the methods employed by the SNS to protect the users' legitimate rights. The results obtained through content analysis revealed that the social networking service providers used largely policy and technological means in protecting the users' legitimate rights. From the policy perspective, most of the SNS relied on the clients trust to protect their legitimate rights; closing accounts of those gullible of violating the policy, dissuading the users from spamming, abusing, harassing or violating the user agreement policy or engaging in racist and xenophobic tendencies, predatory behaviour, stalking, hate speech, child pornography or account hijacking. Facebook, in addition, expects the users to adhere to some basic standards of ethical behaviour (Facebook 2012) that are stipulated in a 'statement of rights and responsibilities' and the 'user privacy policy' that govern their relationship with the users. The LinkedIn method of protecting the users' legitimate rights includes controlling the viewing of the customer contact information by other users through the use of profile function. Like Facebook, LinkedIn does not accept abuse of LinkedIn service by the users who could use it to spam, abuse, harass, or otherwise violate the 'user agreement' or 'privacy policy'. The results indicated that Google (2012) prohibits illegal activities including, hate speech, distributing personal 
and confidential information, account hijacking, child pornography, sexually explicit material, violent or bullying behaviour and so forth. The YouTube Team (2012) was found to rely on the users' trust to protect their [the users] legitimate rights.

\section{Policy and technological gaps in SNS}

The fifth research objective was to identify the policy gaps and technological deficiencies in protecting the users' legitimate rights in the SNS. This research objective like the fourth was addressed through content analysis of the SNS user policies. Moreover, this research objective has two perspectives: the policy gaps and the technological deficiencies. The policy gaps are discussed in this section whilst the technological deficiencies are covered in the next section. The results revealed that the protection mechanisms in the social networking environment were weak, leaving room for infringement of the users' legitimate rights. For example, Hacktivist Group Anonymous in late 2011 threatened an imminent attack to bring down Facebook saying 'everything you do on Facebook stays on Facebook, regardless of your privacy settings'. The results showed that the social networking user policies acknowledge that the service providers are unable to guarantee protection of the users ethical and moral rights. Lundsay (2010) for this reason says the social networking sites open the door to numerous risks including the breaching of confidentiality, conflicts of interest, and misuse of company resources.

Though Facebook user policy states that it does not allow those who are under the age of 13 or sex offenders convicts to use their services, the results did not find any explicit ways of ensuring that only the users who are over 13 years register to use their platform. The sanctions meted to those who violated other users' rights consisted merely disabling their accounts -an inadequate deterrent. The lack of adequate mechanisms for protecting the users' rights in the social networking environments was found to be exacerbated by the fact that no provision was made for compensation when the users' rights were violated. The results found that the user policies indemnified the service providers from litigation arising out of the users' action or inaction. The policy and technical loopholes with regard to protection of the users' legitimate rights opens doors for tremendous room for infringing on the users' legitimate rights. Steel and Vascellaro (2010) observe that the social networking sites can be misused in many ways including disclosure of confidential or other non-public information, fraud, privacy and damage to personal reputation. The results indicated that the users' policies allowed advertising companies to harvest the users' information (NSMNSS 2012) which was unacceptable and a breach of the users' rights.

Facebook's user policy change legitimising divulgence of the users' information without their consent (Facebook Site Governance 2012) in effect mean the users' rights can be violated with impunity. This is exacerbated by the fact that Facebook' pushes the users to make their personal information public in registering on the site. For this reason, Capurro (2012) is concerned that personal data is being controlled and manipulated through surveillance in the SNS. The service provider has an obligation to present the users with clear and understandable explanations of the implications of the change of policy with regard to content that had already been posted and for whom it was meant. Though Facebook justified its change of policy action saying it was necessitated by the poor quality of comments it received from the users, education and training of the users should have preceded this decision. Skog (2011) in a study of the SNS in Scandinavia found that majority of the subscribers who are teenagers with an average of 18 years of age may not have a good grasp of the policies of the SNS to make adequately informed choices. Similarly, Kaplan and Haenlein (2010) are of the view that it remains unclear whether the users in online environments truly understand the implications of a breach to their privacy and whether they understand the privacy policies and terms of service.

Henderson, Hutton, and McNeilly (2012) found in a study using data obtained from Facebook that the 55379405 potential users who were targeted by an advertisement on the site which appeared 220859 times, only 38 users clicked on the advertisement. This result was revealing because prior to the recent Facebook policy change, it had a voting system which purported to give the users a voice in the policy making process. But it would seem that this approach was not an effective and inclusive way of soliciting the user participation. Moreover, on 01 June 2012 when the users were invited to endorse a governance policy that would see a change from voting system to feedback through regular engagements, only 342632 of the close to one billion users participated accounting for only $0.04 \%$ (Facebook Site Governance 2012). Facebook at the time required 30\% endorsement to effect a change on its user policy. Poor participation by the users could be attributed to the sheer size of Facebook making it difficult for the users to see the advert or simply the users' lack of interest because they do not understand the import of their privacy implications. Scarton (2010) noted in this respect that young people understand the internet very well, but may not understand the ethical boundary issues that surround it. Manders-Huits (2010) asserts that the SNS developers have a duty to protect and promote the interests of their users in autonomously constructing and managing their own moral and practical identities.

\section{Technological weaknesses of the Internet}

The results indicate that besides the policy gaps, there are several technical weaknesses inherent in the internet technology, which expose the users to abuse. Researchers at AT\&T Labs and Worcester Polytechnic Institute in August 2012 found that 12 networking sites including Facebook, MySpace and Twitter had multiple ways that outside companies could access the user data. Kaplan and Haenlein (2010) consequently, decree technical failures to truly support privacy projections. Though the SNS provide the users with controls to manage settings to control who 
access their content, Danazis (2011) is of the view that simply providing fine grained controls for setting their preferences is not sufficient to support privacy as the users find the task of specifying who should access each new piece of content tiresome and cumbersome. Furthermore, the internet's technological weaknesses result in identity thefts, scamming, phishing attacks, account hijacking, spamming, and technical failures. The technical weaknesses of the internet make it difficult for the service providers to verify the integrity, honesty, reliability, and accuracy of the information uploaded by the users. In addition, automated mechanisms such as harvesting bots, robots, spiders, or scrapers easily track and access the users' information.

\section{Conclusion and recommendations}

The results of the study indicated that with the social networking impacting people of varying ages and professional persuasions both in the developed and the nondeveloped world and having quickly gained acceptance and use in education, research, the corporate world, government, politics, professional practice, and in the general society; there were increased concerns about the violation and infringement of the users' legitimate rights. The user trust and technological security features of the internet that the SNS used to protect the users' legitimate rights seemed ineffectual and inadequate.

The outcomes of this study have practical and policy ramifications. The results are expected to create awareness amongst the users through education and training about their obligations, responsibilities and vulnerabilities in the social networking environments with regard to their legitimate rights so that they can make informed choices. The SNS service providers are obliged to provide policy, legal and regulatory instruments to ensure full protection of the users' legitimate rights. Moreover, the users of the social networks should be educated about the policy provisions and the technical capabilities of the internet so that they can know what personal information to upload on the SNS, and be able to specify privacy settings which are sensitive to the social context in which their content can be shared with third parties.

This study relied largely on a literature survey and content analysis of the social network user policies to collect relevant information. The need for the users to give their experiences in the social networking environments in their own words could enrich the outcomes of this study. Besides, this study was only restricted to a handful of the most popular social networking sites but could be extended to cover all social networking sites. In addition, this study only concentrated on legitimate rights of the users in the social networking sites. Future research should be extended to other categories of the social media such as wikis, blogs, RSS and more.

The issue of protecting the users' legitimate rights in the social networking environments needs to find its way onto the annual agenda of WSIS Forum. The Forum monitors and evaluates the progress being made in the context of WSIS Plan of Action. This would enable relevant recommendations to be made for action by the UN member states with regard to protecting the users' legitimate rights in the social networking environments. Besides, governments, civil society and consumer protection agencies as stakeholders have more leverage than individual users to exert pressure on the social network service providers to improve their approaches to protecting the users' legitimate rights. These stakeholders should therefore become more involved in advocating for respect of the users' legitimate rights by the social networking service providers. The service providers who have received certification from accrediting agencies can be relied upon to provide a more trusted social networking environment. For example, LinkedIn has secured TRUSTe's Privacy Seal award signifying that its privacy policy and practices comply with transparency, accountability and choice with respect to the collection and use of the users' personal information. The users of the social networking sites should be encouraged to register with the social networking service providers that have received accreditation for compliance.

\section{Acknowledgements Competing interest}

The author declares that he has no financial or personal relationship(s) that may have inappropriately influenced him in writing this paper.

\section{References}

Arico, J., 2011, 'Hackers threaten to take down Facebook', viewed 26 march 2012 from http://www.mobiledia.com/news/115338.html

Backstrom, L., Dwork, C. \& Keinberg, J., 2007, 'Wherefore art thou R3579X?: Anonymous social networks, hidden patterns, and structural steganography', Paper presented at the International World Wide Web Conference, May 8-12, 2007, Banff, Alberta, Canada.

Boyd, D., 2007, 'Why youth (heart) social networking sites: The role of networked publics in teenage social life', in D. Buckingham (ed.), Youth, identity and social media', pp. 119-142. MIT Press, Cambridge, MA.

Buchanan, E.A., 2012, 'Internet research ethics (Stanford encyclopedia of philosophy)', Journal of International Commercial Law and Technology 4(40), 238-251.

Capurro, R., 2010, 'Global intercultural information ethics from an African perspective', Keynote address presented at the Second African Information Ethics Conference 2010, University of Botswana, Gaborone, 6-7 September.

Capurro, R., 2012, 'Ethical issues of social networks in Africa', Keynote address presented at the social networking sites conference, 2012, Kievets Groon Conference Centre, Pretoria, South Africa, 2-7 September.

Chauke, G., 2012, 'South Africa: The power of social networking sites in education' viewed 27 March 2012, from http://allafrica.com/stories/201203130926.html

Corbet, P., 2010, 'Facebook demographics and statistics report 2010: 145\% growth in 1 year', viewed 3 April 2012, from http://www.istrategylabs.com/2010/01/ facebook-demographicsand-statistics-report-2010-145-growth-in-1-year/

Danezis, G., 2009, 'Inferring privacy policies for social networking services', AISec 09, Chicago, IL. eBizMBA, 2011, Top 15 most popular social networking websites, viewed 3 April 2012, from http://www.ebizmba.com/articles/social-networkingwebsites

Facebook, 2012, Statement of rights and responsibilities, viewed 29 March 2012, from https://www.facebook.com/legal/terms

Facebook Site Governance, 2012, How can 1 bn users have their say in how their data is used?, viewed 23 November 2012, from http://www.siliconrepublic.com/newmedia/item/30371-facebook-site-governance/

Farmington, C., 2012, Social networking sites boom and rise of affordable handsets to double mobile broadband market revenue in West and Central Africa by 2017, viewed 17 March 2012, from http://finance.yahoo.com/news/social-mediaboom-rise-affordable-180000289.html

Google, 2012, User content and conduct policy, viewed 29 March 2012, from: http:// www.google.com/intl/en/+/policy/content.html

Giles, D., 2006, 'Constructing identities in cyberspace: the case of eating disorders', British Journal of Social Psychology 45, 463-477. http://dx.doi. org/10.1348/014466605X53596, PMid:16984715 
Gosier, J., 2012, Social networking sites in Africa: Mobile innovations, viewed 28 March 2012, from http://www.readwriteweb.com/

Harmington, M., 2010, 'Care ethics, friendship and Facebook', in D.E. Wittkower (ed.), Facebook and Philosophy, pp. 135-145, Open Court, Chicago.

Hart, H.L.A., 1994, The concept of law, 2nd edn., Clarendon Press, Oxford.

Henderson, T., Hutton, L. \& McNeilly, S., 2012, Ethics in online social network research, FRRIICT case study report, viewed 23 November 2012, from http://torrii. responsible-innovation.org/case-studies/ethics-online-social-network-research. htm

Kaplan, A. \& Haenlein, M., 2010, 'Users of the world unite: The challenges and opportunities of social media', Business Horizons 53(1), 59-68. http://dx.doi. org/10.1016/j.bushor.2009.09.003

Katlic, T., 2012, Facebook user growth rates in Africa, viewed 27 November 2012, from http://www.oafrica.com/statistics/facebook-user-growth-rates-in-africa-june2010-december-2011

Lewis, B.K., 2010, 'Social media and strategic communication: Attitudes and perceptions among college students', Public Relations Journal 4(3), Summer, 2010.

Light, B., McGrath, K. \& Griffiths, M., 2008, 'More than just friends? Facebook disclosive ethics and morality of Technology', Proceedings of the Internationa Conference on Information Systems, Paris. ICIS 2008 Proceedings, paper 193, viewed 7 March 2013, from http://aisel.aiselnet.org/icis 2008/193

LinkedIn Corporation, 2012, Privacy policy, viewed 29 March 2012, from http://www. linkedin.com/static?key=privacy_policy

Lovink, G., 2011, Networks without a cause: A critique of social networking sites, Polity Press, Cambridge

Lundsay, J., 2010, 'Managing the workplace ethics of social networking sites', viewed 26 March 2012, from http://www.corporatecomplianceinsights.com/managing26 March 2012, from http://www.corpor
the-workplace-ethics-of-social-media/

Manders-Huits, N., 2010, 'Practical versus moral identities in identity management, Ethics and Information Technology 12(91), 43-55. http://dx.doi.org/10.1007/ s10676-010-9216-8

Mason, R.O., 1986, 'Four ethical issues of the information age', Management Information Systems Quarterly 10(1), 5-12. http://dx.doi.org/10.2307/248873

Mathen, M., 2012, 'Social networking sites: Enhancing customer experience', Botswana Guardian, 16 March 2012, p. 8.

Mill, J.S., 1969, 'Utilitarianism', in J. Robson (ed.), The collected works of John Stuart Mill, vol 10, p. 203, Routledge \& Kegan Paul, London.

Nissenbaum, H.F., 2004, 'Privacy as contextual integrity', Washington Law Review 79(1), 119-157
NSMNSS, 2012, Blurring the boundaries-new social media, new social science? viewed 23 November 2012, from http://nsmnss.blogspot.com

Onyango, E., 2012, 'Kenyans second top tweeters in Africa', Daily Nation, 26 January 2012, viewed 7 March 2013, from http://www.nation.co.ke/Tech/Kenyanssecond-top-tweeters-in-Africa/-/1017288/1314162/-/ux3kf3/-/index.html

Privacy Rights Clearing House, 2012, Social networking privacy: How to be safe, secure and social, viewed 23 November 2012, from https://www.privacyrights.org/ social-networking-privacy

Rice, A., 2011, 'Students push their Facebook use further into course work', viewed 26 March 2012, from http://chronicle.com/blogs/wiredcampus/students-pushtheir-facebook-use-further-into-academics/33947

Scarton, D., 2010, 'Google and Facebook raise new issues for therapists and their clients', viewed 23 November 2012, from http://www.washingtonpost.com/wpdyn/content/article/2010/03/29/AR2010032902942.html

Smith, T., 2011, 'World map of global social networking sites usage', viewed 27 March 2012, from http://wearesocial.net/blog/2011/06/world-map-global-social-mediausage/

Skog, D., 2011, 'Ethical aspects of managing a social network site: A disclosive analysis', International Review of Information Ethics 16(12), 27-32.

Steel, E. \& Vascellaro, J.E., 2010, 'Facebook, MySpace confront privacy loophole', viewed 23 November 2012, from http://online.wsj.com/article/SB10001424052 748704513104575256701215465596.html

Twitter, 2012, Guidelines for law enforcement, viewed 29 March 2012, from http:// support.twitter.com/entries/41949-guidelines-for-law-enforcement\#

Vallor, S., 2010, 'Social networking technology and virtues', Ethics and Information Technology 12(92), 157-170. http://dx.doi.org/10.1007/s10676-009-9202-1

Van den Eede, Y., 2010, 'Conservatism of mankind or idle talk? A pragmatist approach to social networking sites', Ethics and Information Technology 12(2), 195-206.

Weiss, T., 2008, 'Social networking sites still on rise: Comparative global study', viewed 27 March 2012, from http://www.trendsspotting.com/blog/

Wellman, C., 1995, Real rights, Oxford University Press, New York.

World Summit on the Information Society (WSIS), 2005, Plan of action, viewed 28 March 2012, from http://www.itu.int/wsis/docs/geneva/official/poa.html\#c10

YouTube Team, 2012, YouTube community guidelines, viewed 29 March 2012 from http://www.youtube.com/t/community_guidelines

Zabala, S., 2012, 'I'm wired, therefore, I exist. But your existence started to belong to others?', viewed 27 November 2012, from http://www.newstatesman.com/scitech/sci-tech/2012/07/im-wired-therefore-i-exist 